\title{
GÉNERO E JORNALISMO PARLAMENTAR EM PORTUGAL
}

\author{
Carla Baptista \\ Centro de Investigação Media e Jornalismo (CIMJ). Faculdade de Ciências Sociais e Humanas da \\ Universidade Nova de Lisboa. Email: carlamariabaptista@gmail.com
}

Resumo: Partindo de entrevistas realizadas a 15 repórteres parlamentares e deputadas portuguesas, no âmbito de uma investigação realizada ao abrigo do projeto Política no Feminino: Políticas de Género e Estratégias de Visibilidade das Deputadas Parlamentares (Refa: PTDC/CCI-COM/102393/2008), este artigo procura compreender os défices de protagonistas femininas e temáticas relacionadas com o género na cobertura jornalística do Parlamento em Portugal. As rotinas produtivas do jornalismo parlamentar, aceleradas pelo ambiente digital e pela profissionalização das fontes de informação na política, conjugadas com enquadramentos noticiosos centrados no conflito e com a predominância histórica de interlocutores masculinos, ajudam a explicar o desinteresse dos jornalistas parlamentares pela cobertura de iniciativas legislativas sobre políticas de género.
Palavras-chave: Género; Jornalismo Parlamentar; Mulheres Deputadas

Abstract: This paper discusses the visibility deficit of female deputies and gender policies in the press coverage of the Portuguese Parliament. The productive routines of parliamentary journalism, fostered by digitalization and the professionalization of political sources, intertwined with news frames centred in party conflict and a persistent dominance of male protagonists in politics, are the factors beyond an historic indifference of journalists regarding the coverage of gender issues under parliamentary initiatives. The methodology is based in 15 in-depth interviews with parliamentary reporters and female deputies, conducted under the research project "Politics in the Feminine. Gender Policies and Visibility Strategies of Portuguese Female Deputies" (Ref": PTDC/CCICOM/102393/2008). 
Keywords: Gender, Parliamentary Journalism; Female Deputies

\section{Introdução}

A pesquisa sobre desigualdade de género na política remonta à segunda metade do século XX mas desenvolveuse e diversificou-se de forma acelerada nas últimas duas décadas, permitindo conhecer melhor os comportamentos e as atitudes das mulheres relacionadas com as escolhas partidárias e os modos de participação em vários momentos da vida política, nomeadamente durante campanhas eleitorais, eleições e desempenho de cargos, bem como em diversos contextos e instituições políticas (Manza e Brooks, 1998; BoxSteffensmeier et al., 2004; Kaufmann, 2006). Em Portugal, os défices de visibilidade das mulheres na representação jornalística do Parlamento permanecem elevados, apesar da feminização das bancadas parlamentares, resultado da aprovação da Lei da Paridade, em 2006. Esta estabelece que as listas para as eleições legislativas, europeias e autárquicas devem assegurar a representação mínima de $33 \%$ para cada um dos sexos. A presença de mulheres em cargos no governo ou de liderança partidária é ainda mais restrito, mas este artigo irá focar-se apenas no caso da Assembleia da República.

Em termos teóricos, encetamos uma síntese entre os contributos da sociologia, problematizando as razões para a desigualdade de género na representação política através da relação entre fatores do lado da "oferta" (que aumentam a pool de mulheres com experiência e vontade para competirem na política), fatores do lado da "procura" (que as excluem através de processos de recrutamento ou sistemas eleitorais discriminatórios) (Randall, 1987; Norris, 1997; Paxton, 1997) e a análise histórica das transformações afetando a cobertura jornalística do Parlamento em Portugal. No contexto do jornalismo parlamentar, pretendemos debater o papel dos media na promoção de uma efetiva igualdade de género, perspetivada para lá da questão das "quotas", assegurando o debate no espaço público das temáticas sobre 
género e a visibilidade das protagonistas envolvidas nessas propostas legislativas.

Esta reflexão decorre do projeto de investigação Política no Feminino $^{1}$, desenvolvido no Centro de Investigação Media e Jornalismo, centrado na identificação das estratégias de visibilidade adotadas pelas parlamentares portuguesas no âmbito das iniciativas legislativas promotoras de políticas de igualdade de género. Foram realizadas 15 entrevistas de fundo com deputadas e repórteres parlamentares, com o objetivo de compreender como se relacionam os dois grupos profissionais e quais as perceções mútuas sobre a visibilidade e a importância das questões de género.

\section{Funções do jornalismo nas sociedades democráticas}

Do ponto de vista da organização da vida coletiva, o

1 Projeto Política no Feminino: Políticas de Género e Estratégias de Visibilidade das Deputadas Parlamentares, Ref루: PTDC/CCICOM/102393/2008, financiado pela FCT, coordenado por Ana Cabrera (CIMJ). jornalismo não está dispensado de responsabilidades sociais e políticas. A sua legitimidade social, historicamente conquistada e em permanente atualização, radica na crença de que o jornalismo cumpre uma ação importante nas sociedades democráticas, devendo adotar valores éticos e normas deontológicas que assegurem o equilíbrio polifónico das vozes representadas, a justiça do relato produzido e a relevância pública dos temas abordados. No quadro geral das teorias normativas dos media, os papéis atribuídos ao jornalismo incluem providenciar aos cidadãos a informação e a opinião relevantes para a tomada de decisões no âmbito da sua vida cívica, bem como promover um fórum para o debate público inclusivo, significativo e justo relativamente aos pontos de vista em disputa (Clifford et al., 2009).

O ideal da transparência e da pluralidade que orienta as sociedades contemporâneas democráticas sugere quatro papéis ou funções para os media: monitorizar e vigiar o poder económico e político, recolhendo e distribuindo informação relevante para o público; 
facilitar a disputa argumentativa e contribuir para um debate esclarecido que fortaleça a sociedade civil; radicalizar no sentido de apoiar a mudança e promover as vozes que suportam a reforma social; colaborar no estabelecimento de pontes e parcerias entre os jornalistas e os vários centros de poder, incluindo o Estado.

Os jornalistas exercem estas tarefas num determinado quadro de valores éticos forjado por ideais normativos e cuja operacionalidade é vivida de forma mais ou menos intensa em função de motivações e sensibilidades individuais, mas também de orientações editoriais específicas de cada meio de comunicação social. Os resultados recolhidos junto dos jornalistas parlamentares entrevistados no âmbito do projeto Política no Feminino revelam como os valores deontológicos são valorizados e refletidos na prática profissional. A natureza de cada meio de comunicação social (pública ou privada, impresso ou audiovisual, generalista ou especializado) interfere na forma como esta relação entre valores e práticas é
146

pensada e traduzida numa cobertura jornalística com diferentes abrangências, interesses e enquadramentos.

Outro aspeto relevante enfatizado pela investigação foi a constatação de mudanças significativas na rotina dos repórteres parlamentares causadas pela naturalização do paradigma digital, pela convivência com os canais de televisão noticiosos a emitir $24 \mathrm{~h}$ e pela profissionalização das fontes de informação institucionais e partidárias representadas na Assembleia da República. $\mathrm{P}^{2}$., um repórter veterano a trabalhar para a agência nacional de informação, Lusa, baseado no Parlamento desde 1998, sublinha:

A Lusa tem obrigações maiores do que os outros órgãos de comunicação, mas não se dá tudo o que acontece...tem de haver um critério de bom senso. A questão do pluralismo é essencial. Deve selecionar e ter um critério noticioso mas, como serviço público

\footnotetext{
2 As identidades dos jornalistas são referidas apenas pela inicial do nome próprio.
} 
noticioso, não pode deixar de cobrir acontecimentos que os outros podem deixar de fora.

S., uma jornalista que integra a equipa de repórteres parlamentares da rádio pública Antena 1 desde 1996, destaca os valores orientadores das suas escolhas noticiosas:

$$
\begin{aligned}
& \text { A Antena 1, por ser serviço } \\
& \text { público, tem mais } \\
& \text { responsabilidades e, além } \\
& \text { disso, temos sempre o } \\
& \text { constrangimento do tempo em } \\
& \text { rádio. Para não sermos } \\
& \text { acusados de não garantir o } \\
& \text { pluralismo, temos } \\
& \text { preocupação de dar o ponto de } \\
& \text { vista de todos os partidos. Mas } \\
& \text { também há a lógica } \\
& \text { informativa: se o partido X } \\
& \text { não disse nada, não vou pôr. } \\
& \text { Existe preocupação com o } \\
& \text { equilíbrio, sem perder o } \\
& \text { critério da notícia. }
\end{aligned}
$$

J., uma jornalista parlamentar com 20 anos de profissão, a trabalhar para a TSF, uma rádio privada com forte pendor informativo, acrescenta a necessidade de respeitar o cânone da objetividade:

Antigamente, tinhas uma comissão, tinhas um debate, era uma coisa de cada vez, às vezes duas...agora tens um plenário, duas conferências de imprensa, uma a seguir à outra...O tempo que sobra para tratares as tuas histórias fica reduzido. Há coisas que não se podem deixar cair. Cada jornalista tem de se dividir em " $n$ " para conseguir chegar a tudo. Começas de manhã e vais em sessões contínuas. No meio deste carrossel, tu parares, respirares, dares opinião.... até que ponto é que eu posso opinar?

No estudo que conduziu sobre a forma como os jornalistas avaliam e decidem a noticiabilidade dos acontecimentos, Herbert Ganz (1980) constatou que, para a maioria, as notícias "deviam ser sobre indivíduos e não sobre grupos ou processos sociais."3 Reconhecendo

a

\footnotetext{
${ }^{3}$ Ganz, Herbert (1980). Deciding What's News,
} 
multiplicidade de valores existentes em cada notícia, Ganz encontrou oito padrões, a que chamou os "valores persistentes", designadamente: etnocentrismo, democracia altruísta, capitalismo responsável, pastoralismo, individualismo, moderação, ordem social e liderança nacional. ${ }^{4}$ Interrogando-se sobre a origem destes valores que formam um ideário relativamente cristalizado, globalizado e estruturante das escolhas e dos enquadramentos jornalísticos, assegura que não são intrínsecos à profissão e alguns têm origem nas próprias fontes de informação com as quais os jornalistas estabelecem relações profissionais.

Importa-nos reter estes dois traços distintivos do jornalismo - por um lado, a aparente filiação ideológica numa retórica "progressista"; por outro, a permeabilidade com os valores das fontes "poderosas" - para compreendermos as razões pelas quais um objetivo empático no contexto de uma democracia ocidental, como é a

Vintage Books Edition: New York, p. 8.

${ }^{4}$ Idem, p. 42. igualdade de género no âmbito da participação na política, continua a ser percecionado como pouco estimulante.

S., editora do jornal Público, antiga jornalista parlamentar, corrobora a diminuta relevância atribuída aos temas da igualdade de género pela agenda jornalística:

Eu tenho uma grande batalha aqui no jornal que é fazer com que as questões que dizem respeito aos direitos de género e às desigualdades de género sejam tratadas. Isso é uma coisa que, mesmo na Assembleia, quando comecei a tratar desses assuntos, ninguém ligava nenhuma. Ainda hoje não há uma sensibilidade para estas questões.

Uma das características das fontes "poderosas" é a facilidade de acesso aos media. Ganz refere que raramente estas fontes usam o seu poder para pressionar os jornalistas. Geralmente, usam-no para "criar 
notícias adequadas" do trabalho jornalístico, aqueles que têm a última palavra no que diz respeito à seleção das notícias - em regra, são os diretores e os editores - têm geralmente pouco contacto direto com as fontes de informação. Em todas as áreas do jornalismo, os cargos de chefia conduzem a um relativo isolamento ou desimplicação dos acontecimentos e processos que são noticiados e o contacto com as fontes é deixado quase em exclusivo aos repórteres.

No caso do jornalismo parlamentar, os repórteres têm gozado historicamente de uma grande margem de autonomia. $\mathrm{O}$ processo de institucionalização da democracia portuguesa trouxe o Parlamento para o centro da vida política, intensificando as dinâmicas desenhadas pelos resultados eleitorais e pela ação dos grupos parlamentares e dos seus protagonistas no decurso das legislaturas. Os antigos e atuais repórteres parlamentares entrevistados no âmbito deste trabalho

${ }^{5}$ Idem, p. 119. No original: "Powerful sources rarely use their power to bully their way into story lists; indeed, they use their power to create suitable news". partilham a convicção de que raras vezes o seu trabalho sofreu condicionamentos explícitos por parte das direções editoriais ou de responsáveis políticos.

A liberdade experimentada na escolha dos temas e dos enquadramentos é uma variável que surge assinalada de forma consistente nos testemunhos recolhidos. Joga um papel positivo no grau de satisfação pessoal destes profissionais, sendo uma das razões mais invocadas para explicar a sua longa permanência no Parlamento. D., um jornalista veterano que iniciou a carreira ainda antes do 25 de abril na área do Desporto, integrando posteriormente a equipa de repórteres parlamentares do semanário Expresso, relata:

Tive sempre autonomia absoluta. Nunca me disseram “faz assim ou faz assado". É possível que haja editores que condicionem os repórteres. A mim, nunca ninguém me leu as frases, no sentido de ler para emendar (...) Como trabalhei em jornais desportivos, ia fazer as cabines. Nos jornais 
desportivos, um ia fazer a

crónica do jogo e o outro ia fazer as cabines. $\mathrm{O}$ que eram as cabines? Eram as declarações dos bastidores. Acho que fui para a Assembleia fazer as cabines.

S. iniciou a cobertura da Assembleia da República para o Público em 1995 e sublinha a importância da livre circulação nos espaços informais da Assembleia, nomeadamente nos corredores que rodeiam a sala do hemiciclo, designados por Passos Perdidos, para obter notícias e cumprir os objetivos de quem procura fazer mais do que o mero relato da agenda parlamentar:

Para além do plenário, havia um trabalho de corredores, aquilo a que eu chamava "fazer piscinas", que é andar ali nos corredores a ver em quem é que tropeças. Porque é assim que se faz o jornalismo parlamentar: andas à procura de nada e andas à procura de tudo, passas pelas pessoas e começas a falar e, na conversa, as notícias acabam por fluir.
150

Como todo o jornalismo de fontes, tens de investir muito na conversa, muitas vezes sem nenhum objetivo, mas alimentas uma relação para que, um dia, quando existir a notícia, ela acabe por te cair no colo.

Foi o jornal diário Público, surgido em 1992, que introduziu a exigência de antecipação na cobertura da Assembleia da República, mas esta tornou-se obrigatória para os restantes jornalistas da imprensa de referência. P. começou a fazer reportagem parlamentar para o Diário de Notícias no início da década de 1990 e recorda as dificuldades sentidas quando $\mathrm{o}$ jornal, após a privatização em 1992, começou a lutar pelas chamadas cachas $^{6}$ :

Fui para o Parlamento na altura em que o Público estava numa dinâmica agressiva de cobertura e as televisões privadas acabavam de nascer a SIC e a TVI. O DN ainda

\footnotetext{
${ }^{6}$ Termo da gíria jornalística que designa uma informação exclusiva.
} 
estava muito preso à cobertura tradicional do Parlamento, que era fazer só o que se passava no plenário. Houve ali um choque, porque eu comecei a tentar encontrar fontes de informação fora do plenário, conseguir informações em primeira mão, tentando adiantar coisas que ainda não estavam na ordem do dia (...) Fazer os corredores era tentar perceber como é que os diplomas chegam ao Parlamento, qual é a negociação que existe à volta dos documentos que chegam à Assembleia, estar mais atento às comissões parlamentares às quais não se dava ainda muita importância.

Além do elevado grau de autonomia, os repórteres parlamentares valorizam outras características consideradas estimulantes do seu trabalho, como refere J.:

A grande vantagem que vejo aqui na Assembleia é teres de descobrir a notícia. Tens várias versões, tens um
151

acontecimento, tens um diploma, uma ideia e, a partir daí, tens de construir uma matéria. No princípio, foi isso que me custou mais a apanhar. Perceber que é preciso escolher. Não é como estar na redação, onde as coisas já chegam mais ou menos digeridas, com um caminho apontado. Aqui há sempre várias coisas a acontecer ao mesmo tempo e é preciso discernimento para perceber o que é notícia.

P. salienta igualmente a vitalidade e a complexidade do Parlamento enquanto espaço noticioso:

Quando entrei, tive $\log$ a noção de que era um espaço particular e um grande desafio profissional, porque ali tem-se contacto com todas as áreas políticas. Pelo Parlamento passa tudo o que é legislação, temos contacto com todo o tipo de assuntos.

A multiplicação de acontecimentos, a diversidade de temas 
abordados diariamente e a premência ditada pelo cumprimento dos tempos ligados às rotinas de fecho, no caso das publicações escritas, ou emissão, no caso das rádios e das televisões, imprimem um ritmo de trabalho acelerado e obrigam os jornalistas a fazer uma gestão pragmática do tempo e dos contactos com as fontes de informação.

J., editor da secção de Política do Diário de Notícias, destaca a centralidade do Parlamento na obtenção de informação política:

Todo o jornal tem de passar pelo Parlamento. Mesmo os jornalistas que acompanham outros dossiers, como a Saúde, a Educação, a Energia, têm de ter as comissões parlamentares na sua lista de entidades a cobrir porque os deputados têm acesso a muita informação.

F., jornalista do semanário Expresso, define a forma como avalia os deputados:

Ponto um: que seja boa fonte e me dê histórias. Como o
Parlamento lida com todos os assuntos, ninguém é especialista em Parlamento porque o Parlamento é tudo. Para mim, o mais importante é ter um deputado que me explique o que está em causa, qual é a sua posição e a posição dos outros partidos. Acontece cair-se num tema de que não se sabe nada. Ser especialista de Parlamento é saberes a quem recorres, como é que as coisas funcionam. $\mathrm{O}$ Parlamento é muito gestão de tempo. Às vezes, podes estar a acompanhar três comissões ao mesmo tempo.

Num ambiente complexo, em constante mudança, permeável ao jogo instável da política, onde a informação especializada circula abundantemente, os jornalistas precisam de estabelecer relações de confiança com as suas fontes de informação, cujo anonimato é com frequência protegido, sempre que o assunto envolve matéria mais sensível. P. considera que o tipo de jornalismo parlamentar que busca a compreensão 
dos processos de tomada de decisão política, mais do que o relato da ação política, obriga ao resguardo das fontes de informação:

A maior parte desse tipo de informação é de fontes anónimas. O jornalista tem de aferir se a fonte é credivel para poder acreditar na informação. Uma prática dos jornalistas é confrontarem várias pessoas que estiveram na mesma reunião, cruzam a informação de várias pessoas. Mas obviamente que, na maior parte das vezes, não podem identificá-las.

Os temas relacionados com políticas de género têm sido abordados no Parlamento de forma episódica, emergindo em debates específicos e iniciativas dispersas. Esta forma particular de discussão não convoca a formação de deputadas ou deputados especialistas, capazes de esgrimir uma argumentação mais "técnica" e menos "política", que os jornalistas tendem a associar à defesa de convicções pessoais minoritárias e menos representativa de

\section{3}

uma conceção alargada de "interesse público".

A construção de uma carreira parlamentar e a conquista da visibilidade mediática ligada ao exercício do cargo exigem permanência, competência técnica e política reconhecida pelos pares, fluência com temas específicos presentes na agenda política, bem como contínuas oportunidades de exposição e intervenção. A ocupação de cargos de liderança, desde a direção de bancada até à presidência de uma comissão parlamentar, é um aspeto central na determinação das escolhas que os jornalistas fazem dos seus interlocutores ${ }^{7}$.

John Corner (2003) refere como a evolução da política moderna tende a posicionar os políticos como membros

\footnotetext{
7 Para uma caracterização em profundidade da distribuição dos mandatos parlamentares e da ocupação dos cargos de liderança ou presidência por mulheres, desde 1975, ver o artigo de Carla Martins, "O género na Assembleia da República em 36 anos de democracia: Parlamento mais paritário mas ainda um "clube masculino". In Media e Jornalismo, $\mathrm{n}^{\circ} 21$, vol.11, $\mathrm{n}^{\circ}$ especial online, junho de 2012., disponível em ttp://www.youblisher.com/p/422079-O-genero-naassembleia-da-republica-em-36-anos-de-democraciaparlamento-mais-paritario-mas-ainda-um-clubemasculino-Carla-Martins/
} 
de uma elite administrativa, de quem se espera desempenhos apropriados no quadro das respetivas instituições, relegando para segundo plano a figuração do político como persona, exigindo uma tradução performativa em gestos físicos, posicionamentos morais ou prestígio intelectual. Esta tendência é visível na cobertura jornalística mais recente do Parlamento e nas formas de apreciação dos deputados e das deputadas mais referidas pelos jornalistas, que demonstram possuir uma aguda consciência das mudanças ocorridas em termos de performance parlamentar e relacionamento mútuo entre os dois campos - o político e o jornalístico.

O jornalismo digital, os canais de notícias 24/24 horas e as redes sociais exigem dos repórteres uma atenção constante e a renovação acelerada dos conteúdos informativos. As rotinas do trabalho parlamentar foram profundamente alteradas, com impactos significativos na forma como os diferentes meios de comunicação social organizam a sua cobertura. Para aqueles que continuam a apostar na
154

política como um ingrediente principal da oferta informativa, a tendência foi a de reforçar as equipas e, nalguns casos, transferir a totalidade da secção de Política para a Assembleia da República (caso da Antena 1). A SIC criou uma redação exclusivamente dedicada à Assembleia da República.

A., repórter parlamentar da SIC desde o início daquela estação, em 1992, destaca as principais transformações:

Até 2008, eu estava aqui e havia reforços consoante a necessidade. Agora, a SIC tem uma redação no Parlamento. Funciona com quatro repórteres parlamentares (...) $\mathrm{O}$ Parlamento aumentou muito a intensidade dos eventos e das notícias. Houve uma sangria desatada de reações e conferências de imprensa. Um género recente, a "reaction", instalou-se como um vírus. Todos os partidos sentem uma enorme necessidade de reagir a quase tudo. Nós, jornalistas, sobretudo das rádios e das televisões, pedimos reações: o 


$$
\begin{aligned}
& \text { primeiro-ministro fala, } \\
& \text { pedimos uma reação, os } \\
& \text { números do desemprego } \\
& \text { sobem, pedimos uma reação. }
\end{aligned}
$$

Embora F., a trabalhar para um jornal semanário, tenha uma preocupação menor com a atualidade dos debates em plenário, refere como diversas alterações regimentais introduzidas nas últimas legislaturas também contribuíram para a revalorização jornalística da matéria política que ocorre dentro do hemiciclo:

Desde que houve a reforma do regimento da Assembleia da República, o plenário ganhou imensa centralidade, porque se criaram novos dispositivos. Os debates mensais passaram a ser quinzenais, e isso permite uma narrativa em contínuo, podes ligar um debate ao outro. Os debates quinzenais desdramatizaram as idas do Primeiro-Ministro ao Parlamento. Tornou-se algo regular, que tem de se seguir sempre. Lembro-me que antes as televisões mobilizavam muitos meios de cada vez que
155

havia debate mensal, parecia o debate do Estado da Nação. O plenário ganhou centralidade porque os partidos puderam passar a fazer debates de urgência e debates de atualidade que são marcados, muitas vezes, de véspera ou até no próprio dia, e obrigam os ministros a estar presentes.

M., editora de Política da Antena 1, considera que o tipo de cobertura parlamentar realizado pelas televisões em particular, pelos canais de informação que emitem em contínuo, muito centrado no direto como dispositivo narrativo e na reação como forma de interpelação dos deputados contribuiu para generalizar um estilo de jornalismo menos reflexivo:

As televisões, pela sua forma de trabalhar, propiciam a superficialidade da reação. O que interessa é ter uma reação a qualquer coisa....e o que é essa reação? Às vezes, não é o mais importante. No tempo televisivo não faz sentido 


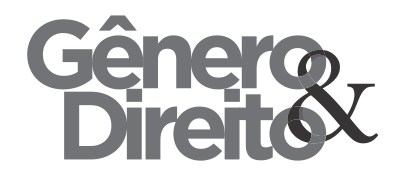

Periódico do Núcleo de Estudos e Pesquisas sobre Gênero e Direito

Centro de Ciências Jurídicas - Universidade Federal da Paraíba

V. 6 - N 01 - Ano 2017 - Mídia, Gênero \& Direitos Humanos

ISSN | 2179-7137 | http://periodicos.ufpb.br/ojs2/index.php/ged/index

aprofundar uma questão, aquilo perde o ritmo (...) $\mathrm{O}$

Parlamento tem uma

enorme vantagem, é um

palco barato. Ocupa-se o

tempo de antena com o que

é conflitual. Se a televisão

deu, eu também tenho de

dar, o jornal também tem

que dar... todos nos

arrastamos uns aos outros.

J. acrescenta a mudança registada no próprio "tempo parlamentar", com regras de gestão do tempo e das intervenções agora mais profissionalizadas, no sentido de serem mais ordenadas e rápidas:

Há debates que duram 20 minutos, com 3 minutos para cada grupo parlamentar, a discussão é rapidíssima. É um extremo em relação ao passado, em que havia debates que se eternizavam. Esse tempo mais longo permitia que as pessoas fossem digerindo o que se passava e, quando a matéria ia para o ar ou era publicada, havia uma reflexão
156 que hoje não existe. As televisões, sobretudo as noticiosas, têm de alimentar a antena 24 horas e o Parlamento fornece-lhes de bandeja horas e horas de emissão, independentemente do valor intrínseco dos debates.

Dentro desta lógica de cobertura, a visibilidade mediática dos deputados e das deputadas constrói-se, cada vez menos, pelo brilhantismo das suas intervenções em plenário ou pela assertividade e eficácia da sua argumentação, esgrimida em duelo livre de ideias; e, cada vez mais, pela assiduidade da sua presença nos diretos televisivos e radiofónicos, proferindo declarações curtas, muitas vezes, em registo de soundbite e cumprindo as instruções das lideranças de bancada, em articulação com as lideranças partidárias. A., ex-repórter parlamentar e comentadora da área política, assinala a perda da aura do deputado ou da deputada que brilhava sozinho/a no palco do hemiciclo:

Havia muito mais trabalho no 
hemiciclo. Hoje as coisas estão

mais burocratizadas e são

menos interessantes desse

ponto de vista (...) havia uma

capacidade de intervenção, de

espontaneidade, de liberdade e

uma iniciativa dos deputados

que hoje não existe. Hoje há um grande controlo. Aliás, acho que a falta de autonomia dos deputados é um dos grandes problemas da vida política portuguesa, estão completamente sujeitos à disciplina partidária.

\section{Deputadas e deputados: desempenhos e interações com os media}

John Corner (2003) menciona duas "esferas" cuja boa gestão é essencial para a obtenção de sucesso na construção de uma carreira política: a primeira inclui as qualidades necessárias para funcionar dentro da instituição e do processo político e não é diretamente mediada pelos media; a segunda, que o autor designa de "pública e popular", envolve todas as dimensões através das quais um político
157

é visto como uma "figura pública", constituindo o espaço de uma "representatividade demonstrável". 8

Corner sugere que podemos ver a primeira esfera como "o local de trabalho" e a segunda como "a loja", cuja importância aumenta em momentos de elevada conflitualidade como, por exemplo, as campanhas eleitorais. Usando esta metáfora, arriscamos dizer que as mulheres deputadas, em geral, cumprem bem no local de trabalho mas vão poucas vezes à loja. Maria de Belém, deputada pelo PS desde 1999, possuindo uma já longa carreira política, que inclui o desempenho do cargo de ministra para a Igualdade entre 1999 e 2000, refere como resiste à adoção de qualquer "estratégia de visibilidade" no relacionamento com os media:

A política é visibilidade e a visibilidade tem riscos. O risco torna-se facilmente em

\footnotetext{
${ }^{8}$ Corner, John, op. cit., p. 74: "The sphere of the public and the popular (...) constitutes the stage where, for instance, politicians develop reputations, draw varying levels of support, are judged as good or bad, undergo meteoric or steady advancement, decline, resign or are sacked. The performance requirements here might be seen as largely presentational ones".
} 
acidente. Um acidente praticado por mulheres tem mais visibilidade jornalística do que um acidente provocado por homens. Os homens são mais desculpabilizados dos erros que cometem do que as mulheres, o escrutínio é mais feroz. Não só o deslize, como a notícia enviesada. Até pode não haver deslize nenhum, mas há todo o gosto em enviesar a notícia quando se trata da atuação política de uma mulher (...) Não tenho estratégia nenhuma de visibilidade por um motivo: a estratégia normal de visibilidade dos homens na política é terem uma relação muito forte com os jornalistas para passarem informação. Eu só passo a informação que pode ser passada e dou a minha opinião sobre temas políticos quando esta é solicitada.

S., jornalista já referida no texto, faz uma avaliação distinta dos desempenhos femininos e masculinos na Assembleia da República:

Os homens deputados são mais proativos e ocupam o espaço todo, as mulheres não tentam ocupar o espaço. Acham que estão lá por favor, que já é muito bom estarem lá e vão fazendo umas coisas que o líder parlamentar vai autorizando e vai deixando. São muito raras as mulheres que têm uma agenda própria na Assembleia.

O défice de visibilidade mediática das mulheres, em parte consequência do seu afastamento dos cargos de liderança, não se alterou com a aprovação da Lei da Paridade. Esta conclusão é unânime entre os jornalistas parlamentares entrevistados, como ilustram os depoimentos seguintes:

Apesar de haver mais mulheres dentro dos partidos, e de haver uma secretária dos Assuntos Parlamentares e uma Presidente da Assembleia, não se nota o peso político das mulheres nesta legislatura" (J., TSF). 
Vês mais mulheres nas bancadas, mas não vês a produção legislativa correspondente e não há mais mulheres que sejam protagonistas" (S., Antena 1).

Temos uma mulher presidente, a segunda figura do Estado, mas, se olharmos para a presidência das comissões, são todos homens. Volta sempre a mesma questão: temos quotas mas as mulheres não estão nos lugares cimeiros, os principais debates e as principais tarefas não lhes são atribuídas" (A., SIC).

Há mais mulheres deputadas mas é uma coisa artificial, foi imposto por lei. Porque as que se destacavam antes da lei das quotas são as mesmas que se destacam agora. (P., Lusa).

Não consigo explicar porque é que as mulheres continuam na sombra, tirando honrosas exceções. As mulheres boas que têm existido impõem-se por elas. Aquele meio é-lhes hostil. Os homens são levados ao colo e, mesmo assim, são poucos os que sobressaem. Mas que homem é que se impõe no Parlamento? Impõem-se quando estão à frente dos grupos parlamentares. São sempre eles que intervêm. As lideranças parlamentares são muito importantes, os líderes designam quem vai participar nos debates e quem vai ficar à frente das comissões, isso tudo ajuda. (A., Visão).

A visibilidade pública das figuras associadas a certas causas não é um fator negligenciável no quadro da luta política democrática. Jon Simons (2003) argumenta que o processo de construção de legitimidade se joga no plano das administrações e das elites, mas também no terreno da cultura popular. Os media são elementos importantes desse processo, pela sua capacidade de atrair públicos transversais. ${ }^{9} \mathrm{~A}$ capacidade de jogar

\footnotetext{
9 Simons, Jon (2003), "Popular Culture and Mediated Politics: Intelectuals, Elites and
} 
plenamente este jogo na democracia mediatizada exige oportunidades de acesso aos media, mas também um capital cultural e um genuíno desejo de aproximação e comunicação com os cidadãos que não abunda entre as elites intelectuais, jornalísticas e políticas portuguesas. A aparente aridez da agenda feminista relaciona-se mais com esta ausência de predisposição para apresentar e explicitar a diferença (desfavorecendo, assim, o seu convívio e integração com os temas mais naturalizados da política) do que com qualquer desligamento intrínseco dessa agenda com a vida quotidiana.

Outros fatores concorrem, em simultâneo, para a desvirtuação do processo global de comunicação da política parlamentar relativa ao género, com efeitos empobrecedores ao nível do léxico, dos temas e dos protagonistas, para usar tópicos da narrativa jornalística. Neste sentido, ficam

Democracy”, Media and the Restyling of Politcs, Corner, John, Pels, Dick (eds). Sage: London, p. 173.: "The principles of democratic government require competing political publics, however narrowly defined they are in social terms, to immerse themselves in "popular reality" which is a democratised mediasphere".
160

comprometidos quaisquer efeitos positivos gerados pela ação dos media ao nível do aumento do conhecimento do público e da ação coletiva sobre igualdade de género na política. Entre estes, destacamos:

a) as lógicas de poder internas aos partidos que se repercutem na distribuição de cargos dentro das bancadas parlamentares, perpetuando a histórica exclusão das mulheres;

b) os valores noticiosos operados pelos jornalistas, que mimetizam as práticas e as figuras do poder, bem como as suas modalidades de "comunicação da verdade"; 10

c) a escolha formatada das fontes de informação que contam versões dominantes inscritas na memória coletiva sem que o relato jornalístico seja inclusivo e aberto a novas reconstruções e reconfigurações.

$\begin{array}{rrr}\text { As mulheres } & \begin{array}{r}\text { deputadas, } \\ \text { expressão falsamente } \\ \text { unificadora, }\end{array} \\ \text { remete para uma realidade }\end{array}$

10 "Truth-telling practices" é uma expressão usada por Michael Shudson num artigo sobre a forma como a Administração Bush comunicava com os jornalistas e os cidadãos depois dos ataques terroristas de 11 de setembro de 2001. 
extremamente diversa e pouco congregadora dos membros deste grupo. As diferenças políticas, a diversidade das culturas partidárias de filiação e os posicionamentos das respetivas bancadas constroem a identidade profissional das deputadas e orientam os seus percursos, iniciativas e sentido de voto, mais do que qualquer pertença de género.

Os partidos portugueses mantêm com as suas subculturas femininas uma crónica relação de mal estar, partilhado por mulheres e homens. Margarida Salema, jurista, antiga deputada europeia eleita pelo PSD e uma das mentoras do Parlamento Paritário, ${ }^{11}$ conta como esta iniciativa de promoção de uma maior participação das mulheres na política foi negociada

${ }^{11}$ O Parlamento Paritário foi uma iniciativa das eurodeputadas Maria Belo (PS), Margarida Salema (PSD) e Maria Santos (PEV), decorrida na Sala do Senado da Assembleia da República, entre 31 de janeiro e 1 de fevereiro de 1994, cujo objetivo era trazer para a agenda dos partidos, dos media e da sociedade civil a problemática da desigualdade de género e o défice de representatividade das mulheres na política. Para uma informação mais detalhada sobre este tema, ver artigo de Ana Cabrera, Maria Teresa Flores e Maria José Mata em Politica no Feminino, Revista Media e Jornalismo, $\mathrm{n}^{\circ} 21$, número especial online. com o seu partido (PSD):

Os meus contactos foram sempre com a direção do grupo parlamentar. Não houve discussões com mulheres do partido porque o PSD não tem uma estrutura de mulheres. Ao contrário de outros partidos, onde existem estruturas de mulheres centristas, de mulheres comunistas, de mulheres socialistas, com as mulheres sociais-democratas é muito complicado. Eu tentei, com a Amélia Oliveira Martins, e com outras pessoas, nos anos 90, alimentar isso, com a própria Leonor Beleza, que fez um projeto de lei sobre associações de mulheres. Mas é uma coisa muito difícil. $\mathrm{Na}$ época, o PSD tinha um quarto de mulheres militantes, portanto, a representatividade nos órgãos políticos do partido era muito escassa.

No PS, um partido com uma tradição maior de militância de mulheres, e mais progressista na sua orientação relativamente à igualdade de 
género - recordamos que as leis da paridade (Lei $\mathrm{n}^{\mathbf{o}}$ 3/2006), da despenalização do aborto (Lei $\mathrm{n}^{\circ}$ 16/2007) e relativa ao alargamento do casamento civil a pessoas do mesmo sexo (Lei $n^{\circ} 9 / 2010$ ) foram aprovadas por governos de maioria socialista também existem dificuldades à plena participação das mulheres na vida e nas decisões do partido. Maria Belo, então eurodeputada e organizadora do Parlamento Paritário em Portugal, refere:

A única pessoa efetivamente sensível à questão de abrir os lugares a mulheres que tivessem valor político foi o Vitor Constâncio [secretário geral do PS entre 1986-89]. Foi quando ele foi líder do partido que se fez a modificação dos regulamentos para existir mais paridade. Foi o primeiro a querer uma mulher no Secretariado Nacional, e uma mulher que tivesse mostrado alguma coisa. Depois, foi o primeiro que, quando fez listas para o Parlamento Europeu e para a
Assembleia da República, pôs uma mulher na comissão das listas com a missão de obrigar a haver um certo número de mulheres. Escolheu as mulheres que tinham valor e colocou-as nas listas. Não era assim, nem nunca mais foi assim.

Segundo Manuela Tavares (1998), os feminismos contemporâneos ficaram marcados pelo debate entre as defensores da "igualdade" e as partidárias da "diferença" de género. Outros contributos (Ferreira, 1988), no quatro crítico do pós-feminismo, procuraram fazer a síntese, alertando para a necessidade de recusar proposições homogeneizadoras sobre a identidade feminina, organizadas em torno de binómios essencialistas como masculino/feminino, corpo/espírito, essência/aparência, político/político ou, numa versão mais recente oriunda da crítica literária, androcentrismo/ginocentrismo (Showalter, 2002). A defesa de uma especificidade nos modos de expressão das mulheres deputadas, exprimindo um inequívoco modo de pertença 
identitária, parece ultrapassada tanto pela reflexão teórica como pelo quadro de fragmentação ideológica a que a composição política do Parlamento não ficou alheia.

A análise das lógicas de funcionamento das duas instituições que tratamos neste texto - o Parlamento e o jornalismo - remete para a ideia de que ambas permaneceram quase intocadas pelo peso dos debates feministas, vivendo numa paradoxal inconsciência, seja da reivindicação da igualdade, seja da operacionalização da diferença como capital político valorizado pelos partidos e pelos meios de comunicação social. $\mathrm{O}$ estudo confirma a patriarcalidade intrínseca às duas estruturas, prolongando a "violência simbólica" (Bourdieu, 1998) emanada das relações de poder. $\mathrm{Na}$ visão relacional de Bourdieu, estas são a malha basilar sobre a qual se estabelecem as posições sociais. Em nome de uma conceção de cidadania liberal pretensamente universal, que despoja os sujeitos das suas conotações particulares, produzimos uma noção de sociedade civil e reproduzimos uma
163

cultura política que oculta formas de exclusão e dominação. É neste ponto que se interseciona a dificuldade de tematização pelos media das políticas de género.

A proclamada ausência de "estratégias de visibilidade" encetadas pelas deputadas reproduz um dos traços estruturais do movimento político feminista, traduzindo-se numa ausência de violência ou manipulação explícita dos media para afirmar o seu ativismo (Steiner, 2005). Rita Basílio de Simões (2007) encontrou igualmente sinais desta preferência pelo "controlo interno da mensagem, por receio de ela ser corrompida", no decurso da sua investigação sobre as lutas de género no discurso das notícias.

\section{Mulheres deputadas: perfis profissionais sólidos}

Embora a participação desigual de homens e mulheres na vida política seja um objeto de estudo em expansão, não existe consenso sobre as causas explicativas da sub-representação feminina na esfera política-institucional. 
Segundo Meirinho Martins e Pequito Teixeira (2005), estas são genericamente imputadas ao lado da oferta, onde cabem as respostas baseadas na ideia de que as mulheres, enquanto grupo social, carecem de recursos e motivação para obter a igualdade de acesso e participação; ou, ao lado da procura, onde se alinham as argumentações que identificam processos discriminatórios de recrutamento político. Trata-se de uma dicotomia que os autores resumem nas seguintes perguntas: "Porque é a que a política não interessa às mulheres?" e "Porque é que a política afasta as mulheres?"

Os dados quantitativos recolhidos no âmbito do projeto Política no Feminino $^{12}$, complementando estudos anteriores, ${ }^{13}$ demonstram como

12 Os dados estatísticos foram analisados com detalhe por uma das investigadores do projecto na sua tese de doutoramento. Ver Martins, Carla (2015). Mulheres, Liderança Política e Media. Lisboa: Aletheia.

13 Meirinho Martins, Manuel e Pequito Teixeira, Conceição (2005). O Funcionamento dos Partidos e a Participação das Mulheres na Vida Política e Partidária em Portugal. Lisboa: Comissão para a Igualdade e para os Direitos das Mulheres, Colecção Estudos de Género. Ver sobretudo a parte 3, "Desigualdades de
164

uma percentagem significativa das mulheres eleitas para a Assembleia da República, ao longo de 36 anos de democracia (entre 1975 e 2011), possui uma vasta experiência política. Logo na Assembleia Constituinte, em 1975, das 27 deputadas eleitas, 30\% tinham experiência política anterior, neste caso, autárquica, já que se tratava da primeira assembleia democrática após mais de 40 anos de ditadura. Nas VII e VIII legislaturas (1995-2002), correspondentes a outro ciclo político e social da vida portuguesa, com vários anos de integração europeia decorridos e maior familiaridade com a problemática da igualdade de género, a variável da experiência política anterior era ainda mais reforçada.

A consideração de indicadores como a experiência profissional e o grau académico aponta para perfis de mulheres deputadas bastante sólidos. Para além da posse de experiência política, experiência profissional e qualificações académicas elevadas, as mulheres deputadas, em geral,

género nas estratégias e critérios de recrutamento parlamentar". 
constroem uma carreira parlamentar longa, sendo sucessivamente reeleitas. Esta tendência é transversal a todos os partidos. Estes dados reforçam a convicção de que a escassa visibilidade das suas iniciativas parlamentares não reside em quaisquer défices intrínsecos ao grupo, antes deve ser procurada: a) nas dinâmicas estruturais de funcionamento dos partidos; b) nas lógicas de distribuição de cargos e responsabilidades dentro das bancadas parlamentares; c) nas rotinas produtivas dos jornalistas e nas escolhas dos enquadramentos noticiosos.

Relativamente às rotinas produtivas dos jornalistas e às escolhas dos enquadramentos noticiosos, verificámos uma tendência para a dependência das "versões da história" propaladas pelos interlocutores designados pelas lideranças partidárias, bem como para a adoção de enquadramentos narrativos que privilegiam os valores típicos da disputa político-partidária (a luta pelo poder) em detrimento do aprofundamento de temáticas ou processos envolvendo múltiplos atores sociais. As questões de género, embora possam ser ativadas por episódios concretos (por exemplo, de discriminação ou violência), convocam estruturas históricas e dinâmicas evolutivas envolvendo várias dimensões (políticas, legislativas, culturais, económicas) e parecem desalinhar da convenção narrativa dominante no jornalismo parlamentar (como, aliás, desalinham de todos os discursos instituídos). A este propósito, citamos o pensamento de uma sindicalista pertencente ao Conselho Nacional da CGTP que traduz exemplarmente a dificuldade histórica de uma plena assunção da condição feminista em Portugal: "Quando a nível sindical queríamos colocar questões que iam mexer nas mentalidades [como a despenalização do aborto], éramos consideradas feministas."

Não será nunca demasiado sublinhar a existência de um défice histórico ao nível da representatividade parlamentar das mulheres, com

\footnotetext{
14 Tavares, Maria Manuela (1998). Movimentos de Mulheres em Portugal após abril de 1974. Dissertação de doutoramento orientada por Anne Cova, na Universidade Aberta, p. 42. A CGTP é uma central sindical cujo primeiro congresso decorreu em 1975.
} 
clivagens entre os vários partidos. $\mathrm{O}$ percurso da representatividade feminina, sendo globalmente positivo no sentido de um consistente aumento do número de mulheres titulares de mandatos, evoluiu lentamente e apenas na última década da democracia portuguesa inscreveu claramente as mulheres na paisagem parlamentar. Não sendo apenas de números, como procuramos demonstrar, a questão da subrepresentação também é, ou ainda é, uma questão de números.

\section{Considerações finais}

Parafraseando o título do artigo da investigadora brasileira Maria Cecília Garcia (2002) a relação das mulheres deputadas com os meios de comunicação social tem sido "amarga" 15 .

A fraca participação feminina em todos os níveis da administração política, uma tendência transversal à

15 Maria Cecília Garcia (2002). "A Amarga Relação da Mulher com os Meios de Comunicação de Massa". In Schaun, Ângela (organizadora), Género, Midia e Sociedade, Expressão e Arte Editora, pp. 11-21.
166 generalidade dos países, levou Pippa Norris (1985:93) a afirmar que "não se pode dizer que as mulheres enquanto grupo social tenham feito progressos significativos em termos de ocupação de cargos de poder. ${ }^{" 16} \mathrm{~A}$ investigadora aponta fatores institucionais, sócioeconómicos e culturais que interferem com a representatividade das mulheres nas elites políticas. $\mathrm{Na}$ maioria das democracias europeias, as constituições e enquadramentos jurídicos asseguram a possibilidade de uma plena participação das mulheres em todos os domínios da vida pública. Se, na prática, elas continuam situadas na periferia das instituições políticas é porque, como pensam Pamela Paxton e Melanie M. Hughes (2007), persiste uma discriminação velada que constrange uma verdadeira igualdade de acesso e ação. Estas investigadoras remetem a explicação para uma "estrutura cultural e social", sugerindo uma abordagem teórica que inclua fatores do lado da "oferta" e fatores do lado da

${ }^{16}$ Norris, Pippa (1985). "Women's legislative participation in western Europe". In West European Politics, Volume 8, Issue 4, 1985,p.93. 
"procura"17.

A representação mediática das mulheres políticas e a representação jornalística das suas iniciativas desempenham um papel importante na criação, junto do eleitorado, de perceções e atitudes favoráveis que reforçam uma praxis política mais igualitária.

O jornalismo português mudou muito ao longo do período contemplado pelo projeto Política no Feminino. Os temas analisados abrangem a discussão sobre os direitos fundamentais decorrida durante a Assembleia Constituinte, em 1975, passando por duas votações relativas à despenalização do aborto (1998 e 2007), dois debates sobre paridade nas listas concorrentes às eleições europeias, autárquicas e legislativas (1999 e 2006) e por um “epifenómeno" ou "pseudo acontecimento" que lançou

17 Paxton, Melanie, Hughes, M. Melanie, (2007), Women, Politics and Power. Pine Forge Press: London, p. 101: "Supply factors are those that increase the pool of women with the will and experience to compete against men for political Office. Demand factors are characteristics of countries, electoral systems or political parties that make it more likely that women will be pulled into office from the supply of willing candidates". as bases para estas duas últimas discussões, ao conseguir alcançar um elevado grau de atenção mediática: o Parlamento Paritário, em 1994.

Como aspetos positivos, salientamos uma maior diversificação das fontes de informação, com a convocação amiúde de especialistas ou comentadores oriundos da sociedade civil e das organizações de mulheres, chamados a pronunciarem-se sobre os temas em discussão na Assembleia da República, cujo contributo adiciona experiência, realidade e diversidade aos pontos de vista apresentados aos leitores. Mas este movimento para fora do Parlamento ainda é uma prática excecional e, nos últimos anos, fruto das tendências de cobertura jornalística que fomos assinalando ao longo deste texto, não conheceu uma evolução positiva.

A sofisticação da comunicação política não tem contribuído para assegurar a diversidade dos temas e dos protagonistas parlamentares. Pelo contrário, gerou uma concentração da atenção jornalística nos rostos mais conhecidos (em regra, associados às 
lideranças partidárias ou, episodicamente, à presidência de comissões parlamentares tratando de casos mediáticos) e em enquadramentos noticiosos focados no conflito partidário que não procuram situar os factos do dia nas dinâmicas e nos processos sociais subjacentes. Estas escolhas favorecem a "masculinização" do debate político.

Um dos textos mais interessantes sobre as mudanças genéricas e transversais no jornalismo aponta para uma dinâmica tripartida: "tabloidização, tecnologia e verdade"18. Estes conceitos expressam preocupações com a crescente trivialização dos conteúdos; com as mudanças operadas nas práticas e nos valores por via das transformações tecnológicas e com a questão da "verdade" e das modalidades de comunicação de verdade próprias da cultura política contemporânea e reproduzidas pelo jornalismo. À luz deste prima, o jornalismo político parlamentar segue sendo uma espécie

18 Zelizer, Barbie (ed), (2009), The Changing Faces of Journalism - Tabloidization, Technology and Truthiness. Routledge: London and New York. de "oásis": o discurso é sério, centrado nos factos, narrado com sobriedade e rigor, combinando informação com análise. Em geral, não procura, parodiando Michael Serazio"19, "chegar ao coração dos leitores arrancando-lhes a cabeça". No entanto, ainda está longe, utilizando uma expressão de Barbie Zelizer, do "jornalismo que imaginamos".

\section{Referências bibliográficas}

Baptista, Carla (org.) (2012), "Política no Feminino", Media e Jornalismo, 11(21). Centro de Investigação Media e Jornalismo: Lisboa.

Bourdieu, Pierre (1998), A Dominação Masculina. Oeiras: Celta Editora.

Box-Steffensmeier, J. M.; De Boef, S.; Lin, T. (2004), "The Dynamics of the

19 Serazio, Michel, "Rethinking a Villain, Redeeming a Format" (2009). In Zelizer, Barbie (ed), The Changing Faces of Journalism Tabloidization, Technology and Truthiness, Routledge: London and New York, p. 15. A expressão original é: "But if reporters swoon to capture the readers's heart, they cannot fail to attend his or her mind". 
Partisan Gender Gap", American

Political Science Review, 98, 515-528.

Campos, Maria Amélia Clemente (2001), As Mulheres Deputadas e o Exercício do Poder Político

Representativo em Portugal - do pós 25 de Abril aos anos 90. Afrontamento, Coleção Parlamento: Lisboa.

Christians, Clifford G. (2009),

Normative Theories of the Media.

University of Illinois Press: Urbana and

Chicago.

Corner, John; Pels, Dick (eds.) (2003),

Media and the Restyling of Politics.

Sage: London.

Dahlgren, Peter (2009), Media and Political Engagement, Citizens, Communication and Democracy. Cambridge University Press:

Cambrifge, New York.

Espada, Isabel (dir.) (2002), Género e Comportamento Eleitoral, O Eleitorado Português e a Atividade Política das Mulheres. Instituto de Estudos para o Desenvolvimento: Lisboa.
Ferreira, Virgínia (1988), “O Feminismo na Pós Modernidade", Revista Crítica de Ciências Sociais, 24, Universidade de Coimbra.

Franklin, Bob (1994), Packaging Politics, Political Communications in Britain's Media Democracy. Hodder Arnold: London.

Ganz, Herbert (1980), Deciding What's News. Vintage Books Edition: New York.

Kaufmann, K. M. (2006), "The Gender Gap”, PS: Political Science and Politics, 39, 447-453.

Martins, Carla (2015), Mulheres, Liderança Política e Media. Alêtheia: Lisboa.

Martins, Manuel Meirinho; Teixeira, Conceição Pequito (2005), O Funcionamento dos Partidos e a Participação das Mulheres na Vida Política e Partidária em Portugal. Comissão para a Igualdade e para os 
Direitos das Mulheres. Presidência do

Conselho de Ministros: Lisboa.

Manza, Jeff; Brooks, Clem (1998),

"The Gender Gap in U.S. Presidential

Elections: When? Why? Implications?", American Journal of Sociology, 103(5), 1235-66.

Negrine, Ralph (2008), The transformation of political communication, continuities and changes in media and politics. Palgrave Macmillan: New York.

Paxton, Melanie; Hughes, M. Melanie (2007), Women, Politics and Power. Pine Forge Press: London.

Schaun, Ângela (org.) (2007), Gênero, Mídia e Sociedade. Expressão e Arte Editora: São Paulo.

Silveirinha, Maria João (coord.) (2004), As Mulheres e os Media. Livros Horizonte: Lisboa.

Simões, Rita Basílio (2007), A Violência contra as Mulheres nos
Media. Lutas de Género no Discurso das Notícias (1975-2002). Coimbra: Coimbra Editora.

Showalter, Elaine (2002), "A Crítica Feminista no Deserto", in Ana Gabriel Macedo (org.), Género, Identidade e Desejo. Lisboa: Antologia Crítica do Feminismo Contemporâneo. Livros Cotovia, pp. 7-13.

Steiner, Linda (2005), "The Feminist Cable Collective as Public Sphere Activity", Journalism, 6(3), London: Sage, pp 313-334.

Tavares, Maria Manuela (1998), Movimentos de Mulheres em Portugal após Abril de 1974. Dissertação de Doutoramento sob a orientação da professora doutora Anne Cova (manuscrito consultado na Biblioteca Nacional). Lisboa: Universidade Aberta.

Thornham, Sue (2007), Women, Feminism and Media. Edinburgh University Press: Edinburgh.

Zelizer, Barbie (ed.) (2009), The 
Changing Faces of Journalism -

Tabloidization, Technology and

Truthiness. Routledge: London and

New York. 